\title{
Clinical Practice Guidance for Management of Anti HBc Positive Patients
}

\author{
S ALAM $^{\mathrm{a}}, \mathrm{S} \mathrm{ISLAM}^{\mathrm{b}}$, AH KHAN $^{\mathrm{c}}$, M ALAM $^{\mathrm{d}}$, GAZAM $^{\mathrm{e}}$, G MUSTAFA $^{\mathrm{f}}$, M HOSSAIN $^{\mathrm{g}}$, M KHAN $^{\mathrm{h}}$
}

\begin{abstract}
Summary:
Hepatitis B core antibody (Anti $\mathrm{HBc}$ ) is currently considered the most sensitive serological marker for a patient's history of hepatitis $B$ virus (HBV) infection given its long-term persistence in the bloodstream. The serological pattern of isolated Anti HBc (IAHBc) has been of clinical interest over the past several years.,Thegrowing data of IAHBcsuggestingit as a marker for occult HBV infection (OBI). Occult HBV infection defined as $\mathrm{HBV} D \mathrm{DNA}$ detection in serum or the liver by sensitive diagnostic tests in HBsAg negative individuals with or without serologic markers of previous viral exposure. OBI is especially concerned in blood transfusion (BT), organ donation and reactivation of $\mathrm{HBV}$ infection following immunosuppressive therapy. $\mathrm{HBV}$ reactivation depends on viral and host factors. The important clinical implications of IAHBcis in the setting of co-infection with hepatitis $C$ virus $(\mathrm{HCV})$, reactivation risk of $\mathrm{HBV}$ during
\end{abstract}

Introduction:

Hepatitis B Virus (HBV) is a major global public health concern. Over 2 billion people worldwide had been

a. Dr. Shahinul Alam, Associate Professor, Department of Hepatology, Bangabandhu Sheikh Mujib Medical University, Shahbag, Dhaka- 1000

b. Dr. Saiful Islam, Research Assistant. Department of Hepatology, Bangabandhu Sheikh Mujib Medical University, Shahbag, Dhaka- 1000, Bangladesh.

c. Dr. Asma Helen Khan, Medical Officer. Department of Hepatology, Bangabandhu Sheikh Mujib Medical University, Shahbag, Dhaka- 1000, Bangladesh.

d. Dr. Mahabubul Alam, Department of Hepatology, Bangabandhu Sheikh Mujib Medical University, Shahbag, Dhaka- 1000, Bangladesh.

e. Dr. Golam Azam, Associate Professor. Department of Gastrointestinal Hepatobiliary and Pancreatic disorders (GHPD). BIRDEM. Dhaka, Bangladesh.

f. Dr. Golam Mustafa, Associate Professor Department of Hepatology, Bangabandhu Sheikh Mujib Medical University, Shahbag, Dhaka- 1000, Bangladesh.

g. Dr. Motahar Hossain, Hepatology Society. House 64. Road 8A. Dhanmondi R/A. Dhaka.

h. Prof. Mobin Khan, Professor of Hepatology (Rtd). Hepatology Society. House 64. Road 8A. Dhanmondi R/A. Dhaka.

Address of Correspondence: Shahinul Alam, Associate Professor, Department of Hepatology, Bangabandhu Sheikh Mujib Medical University, Shahbag, Dhaka- 1000, Bangladesh. Phone: +8801973007173, Email: shahinu167@yahoo.com

Received: 18 March, 2019

Accepted: 3 Sept., 2019 directly acting anti viral (DAA) therapy in HCV infection which may lead to progression of liver disease and hepatocellular carcinoma (HCC). Antiviral prophylaxis has been recommended in moderate to high risk of reactivation prior to immunosuppressive and biologics. The main goal of therapy is to improve survival and quality of life by preventing disease progression and to prevent consequent development of HCC. It is proposed to perform Anti-HBc test as a screening test prior to blood transfusion, HBVvaccination, $D A A$ and immunosuppressive therapy in addition to HBsAg screening test.

Keywords: Hepatitis B Virus; Hepatitis B virus DNA; Occult hepatitis $B$ virus infection; Hepatocellular carcinoma; Hepatitis B surface antigen,; AntiHBc total; Bangladesh

(J Bangladesh Coll Phys Surg 2019; 37: 196-201) DOI: http://dx.doi.org/10.3329/jbcps.v37i4.43350

infected and 250 million people in world are chronically infectedwith $\mathrm{HBV}^{1}$. Regional prevalence of $\mathrm{HBV}$ is highest in sub Saharan Africa and South East Asia between $5-10 \%{ }^{1}$. Bangladesh belongs to an intermediate prevalent region, which is about $4.2 \%^{2}$. Another study conducted atSavar, a suburban area of Bangladeshrevealed prevalence of $\mathrm{HBsAg}$ is $5.5 \%{ }^{3}$. Hepatitis B core antibody (AntiHBc) is one of the most important serological markers of $\mathrm{HBV}$ infection. In $\mathrm{HBV}$ endemic area prevalence of Anti $\mathrm{HBc}$ is high.In Bangladesh prevalence of AntiHBcamong general population is $31 \%^{2}$, among chronic kidney disease patient is $39.3 \%{ }^{4}$. Another study conducted in Kallyanpur, a densely populated community in Dhaka, Bangladesh explored its prevalence is $47.7 \%$ among 384 healthy subjects ${ }^{5}$. General populations as well as physicians arevery much worried about Anti HBc positivity.: in special situation likeco infectionofHCV and HBV, immunosuppression, blood transfusion, organ donation. No local guide line exists from any professional . So a local guidancefor management recommendation is needed for proper handling of AntiHBc positive cases. 


\section{Methodology:}

We have explored all the online publications available on HVB of Bangladesh from beginning to 2018. We have reviewed the guide lines and recommendations published on HBV and or Anti HBcby professional bodies of Asia Pacific region, European association and United states from 2010 to 2018. Here anti HBc and Anti $\mathrm{HBc}$ totalconsidered as clinically synonymous.

\section{Discussion:}

Anti $\mathrm{HBc}$ as a serological marker

AntiHBc is recognized as an important serological marker forhepatitis B virus infection identifying patients infected with hepatitis B virus infectionand persists for life.,Regardless of whether the HBV resolves or remains chronic. AntiHBc is found in different phases of HBV infection:acute, chronic, resolved HBV infection, occult HBV infection (OBI), as well as false positive cases. Anti $\mathrm{HBc}$ positive with $\mathrm{HBsAg}$ positive indicates ongoing infection. High degree of suspicion with persistently raised transaminases and or chronic liver disease where other causes were excluded would direct for further evaluation. Occult, HBV infection, where low viraemia is detected by HBV DNA in serum or liver. Very rarely hepatitis $B$ virus core $(\mathrm{HBc})$ antigen may persist in the nucleus of hepatocyte. Immunosupression may cause reactivation (reappearance) of HBV infection.

Spectrum of clinical conditions with Isolated Anti $\mathrm{HBc}(\mathrm{IAHBc})$

Current literature has used the IAHBcspecifically to HBsAg-negative, antiHBc-positive patients, often stratifying this population into antiHBs-positive and Anti HBs-negative subgroup ${ }^{6}$.IAHBc can occur for variety of phases.

a. Previous exposure to HBV:It is the most common reason for Anti $\mathrm{HBc}$ positivity. These persons recovered from acute $\mathrm{HBV}$ in past and Anti HBs has waned to undetected level, but some had been chronically infected with HBV for decades (with DNA $20-200 I U / \mathrm{ml}$ ) before clearing HBsAg. They are still in minor risk of developing $\mathrm{HCC}$ like inactive chronic $\mathrm{HBV}$ with undetectable $\mathrm{DNA}^{7,8}$.If IAHBc is confirmed, consideration of subsequent testing should be pursued to evaluate for $\mathrm{OBI}^{9}$.

b. False positive: less commonly antiHBc may be a false-positive test result, particularly in lowprevalence areas ${ }^{10}$. c. Window phase: AntiHBc may be the only marker of HBV infection during the window phase of acute hepatitis B; these persons should be tested for anti $\mathrm{HBc}$ immunoglobulin $\mathrm{M}$.

d. False Negative HBsAg: In case ofHBsAg mutations that leads to false-negative HBsAg with ongoing $\mathrm{HBV}$ infection ${ }^{11}$.In this rare condition Anti $\mathrm{HBc}$ will be positive and HBsAg will be negative.

\section{Occult HBV infection (OBI)}

OBI refers to the presence of HBV DNA in the absence of detectable hepatitis B surface antigen ${ }^{12}$. OBI can be defined by the presence HBV DNA in the serum or liver tissue with either seropositive or seronegativestatus ${ }^{13}$.High risk group for OBI:Blood donors, transplant recipients, patients co-infected with HCV, HIV immunosuppressive therapy or hemodialysis, cryptogenic liver disease, intravenous drug abuser andhealthcare workers ${ }^{15}$.

\section{Types of OBI}

Seropositive OBI: Seropositive OBI is characterized by detection of anti $\mathrm{HBc}$ with or without Anti HBs antibody with detectable HBV DNA ${ }^{12}$.

Seronegative OBI: Seronegative OBI is described by undetectable both Anti $\mathrm{HBc}$ and Anti HBs with detectable HBV DNA ${ }^{12}$.

Most OBI is seropositive butaround $20 \%$ of OBI are seronegative representing a population negative for all serum markerof HBV infection but detectable HBV DNA $^{14}$.

Prevalence:OBI varies worldwide.Prevalence rates of OBI are influenced by several factors as follows: (1) geographic differences (endemicity); (2) Co morbid diseases such as chronic hepatitis $\mathrm{C}$; and (3) and the different diagnostic techniques ${ }^{15}$.OBI was reported higher in HBV endemic area, where $41-90 \%$ people had previous exposure to $\mathrm{HBV}^{16}$.

If IAHBc is confirmed, consideration of subsequent testing should be pursued to evaluate for OBI. Kanget al. ${ }^{17}$ described rates of occult infection ranging from $0 \%$ to $22.5 \%$. They also provided an updated range of $1.7 \%$ to $41 \%$, reporting on subjects who are HBsAg negative, anti-HBc positive, and HBV DNA positive among a sample of studies from 2001 to 2015 around the 
globe. OBI is primarily been associated with the suppression of viral replication and gene expression.However, it has also been seen in patients with mutant forms of HBV with undetectable HBsAg. $\mathrm{OBI}$ is significant in various clinical contexts including viral transmission with blood transfusion and organ donation, reactivation after biologics, chemotherapy, and antiviral and progression of liver disease including HCC.

IAHBc total positivity with or without HBV DNA positive around the world is $7.7 \%$ in Germany ${ }^{18}, 3.7 \%$ in $\mathrm{USA}^{19}, 4 \%$ in $\mathrm{UK}^{20}, 8.2 \%$ in Mexico ${ }^{21}, 22.8 \%$ in India $^{22}, 3 \%$ in Australia $^{23}, 1.7 \%$ in Korea ${ }^{17}, 30 \%$ in $\operatorname{Iran}^{24}, 18.5 \%$ in Egypt $^{25}$ and $16 \%$ in Laos $^{26}$.

Indication of screening HBV DNA

IAHBc cases with regard to the consequence of OBI, for improving the treatment and management, the screening of HBV DNA by real-time PCR should be implemented in the following groups: (1) patients with a previous history of chronic HBV infection; (2) Co infection with HCV or HIV; (3) patients undergoing chemotherapy with anti-CD20 therapy; (4) any recipients of organ transplantation; (5) organ transplant donors; (6) thalassemia or hemophilia patients; 7) health care workers; (8) patients with cryptogenic hepatitis or cryptogenic liver related disease:cirrhosis and HCC and (9) haemodialysis patients ${ }^{13}$.

\section{IAHBc with HCV Co Infection}

Chronic HBV infection along with $\mathrm{HCV}$ co infection accelerates liver diseases progression and HCC. Treatment with DAAs may cause reactivation of HBV. Patients with $\mathrm{HBs} A g$ negative AntiHBc positive are at very low risk of reactivation with HCV DAA therapy ${ }^{27}$. For Anti HBcpositive, HBsAg negative patient monitoring of ALT is reasonable, HBsAg and HBV DNA is recommended if ALT fail to normalize or increase despite declining or undetectable HCV RNA level ${ }^{27}$. Joint American Association for the Study of Liver Diseases and Infectious Diseases Society of America guidelines recommend all patients undergoing HCV DAA therapy be evaluated for $\mathrm{HBV}$ co infection by measuring $\mathrm{HBsAg}$, antiHBs, and antiHBc ${ }^{28}$.

\section{Immunosuppressed conditions}

$\mathrm{HBV}$ reactivation is a key consideration when initiating immunosuppressive therapy. The 2015 American
Gastroenterological Association guidelines summarized the prevention and treatment of $\mathrm{HBV}$ reactivation during immunosuppressive therapy ${ }^{29}$. When considering IAHBc positive patients, the use of antiviral prophylaxis/ preemptive therapy is categorized by level of risk of reactivation, with types of immunosuppression categorized into low,moderateand highrisk groups depending on perceived intensity of therapy and associated risk ${ }^{12}$.

Low risk: Isolated Anti $\mathrm{HBc}$ positive patient treated with Azathioprine, 6 merceptopurine, MTX,Intraarticular steroid, Oral corticosteroid $<1$ week of any dose.

Moderate risk: Isolated Anti $\mathrm{HBc}$ positive patient treated with TNF Alfa I (Infliximab, etanercept, adalimumab, cerolizumab), Cytokine and Integrin inhibitor( abatacept, ustekinumab, natalizumab), tyrosine kinase inhibitor( imatinib, nilotinib), prednisolone $<10 \mathrm{mg}>4$ weeks and with Anthracyclinewith HBsAg Negative(Doxorubicin) High Risk: Isolated Anti $\mathrm{HBc}$ positive patient withB cell depleting agent (Rituximab, Ofatumumab), Anthracycline with HBsAg positive (Doxorubicin, Epirubicin) and with patient treated with $10-20 \mathrm{mg}$ Prednisolone $>4$ weeks.

\section{HCC risk with IAHBc:}

A meta-analysis was conducted on 10 observational studies in 2010 evaluate role of anti-HBc positivity for the risk of $\mathrm{HCC}$ in $\mathrm{HBsAg-negative} \mathrm{subjects} \mathrm{with}$ chronic liver disease ${ }^{30}$. Serum antiHBc, an indirect serological marker of occult HBV infection and may be associated with HCC. Study demonstrates that occult HBV patients have a significantly higher risk of HCC than the antiHBs/antiHBc negative. IAHBc was found to have a significantly higher risk of HCC than with antiHBs positive.

Here it may also be hypothesized that circulating antiHBs may prevent the risk of HCC, most probably by controlling HBV replication. Meta-analysis indicates that, at least for HBsAg-negative/antiHBc-positive patients with chronic liver disease, a more accurate monitoring for $\mathrm{HCC}$ is hypothesized. This is evident for both Asian and non-Asian populations, in different stages of chronic hepatitis, in HCV etiology, and in patients with or without circulating anti-HBs. The risk of HCC seems to be lower in anti-HBs/anti-HBc-positive patients than in those with "isolated" anti-HBc, 
suggesting some inhibitory effect of anti-HBs on occult HBV replication. ${ }^{30}$

\section{Blood transfusion}

Unsafe blood transfusion is one of the routes of transmission for HBV infection. Despite, all blood donations being tested routinely for HBsAg as a marker of transmissible HBV. HBV is transmitted by blood transfusion more frequently than HCV \& HIV. In low prevalent area such as Europe and North America, $<5 \%$ of blood donors are characterized as having occult hepatitis B. On the contrary, occult HBV may be the major cause of transfusion transmitted HBV infection in high prevalence areas. Iranian study demonstratesHBV infection among anti $\mathrm{HBc}$ positive donor in range between $11.3 \%$ and $28.6 \%{ }^{31}$.FDA recommends testing of HBsAg and Anti HBc for blood transfusion and organ donation $^{32}$.

\section{Non liver solid organ transplant recipients}

All patients of non liver solid organ transplantation should be tested for HBsAg, antiHBc, \&antiHBs.HBsAg positivenonliver transplant recipient have a higher mortality rate with liver related complication. All HBsAg positive organ transplant recipients should receive lifelong antiviral therapy tenofovir alafenamide, tenofovir disoproxil fumerate or entacavir. HBsAg negative antiHBc positive non liver transplant recipients should be monitored for reactivation, alternatively antiviral therapy for the first 6-12 months .The period of maximum immunosuppressant, may be considered ${ }^{27}$.Monitoring should be with ALT 3 monthly \& by HBV DNA if ALT rise $^{33}$.

Vaccination of $\mathrm{HBV}$ in Anti $\mathrm{HBc}$ positive person: Clinicians should screen $\mathrm{HBsAg}$, Anti $\mathrm{HBc}$, and Anti $\mathrm{HBs}$ for $\mathrm{HBV}$ in high-risk persons,including persons born in countries with $2 \%$ orhigher HBVprevalence (Table I). Low prevalent countries recommend HBV vaccination in presence of Anti HBcin absence Anti HBs and HBsAg. All Asian countries including Bangladesh have $>2 \% \mathrm{HBV}$ prevalence ${ }^{27}$.

\section{Guidance:}

As per present status of information and evidence to generate guide line is not sufficient for the country. But the following guidance may upgrade the reasoning and decision making in clinical practice.

a. Guidance is required for management of Anti $\mathrm{HBc}$ positive person.

Table-I

$H B V$ serological test, interpretation and vaccination ${ }^{34} ?(R E F)$

\begin{tabular}{lccc} 
Test & Result & Interpretation & Vaccination needed \\
\hline HBsAg & negative & susceptible & Yes \\
anti-HBc & negative & & \\
anti-HBs & negative & & no \\
HBsAg & negative & Immunedue to \\
anti-HBc & negative & vaccination & \\
anti-HBs & positivewith $\geq 10 \mathrm{mIU} / \mathrm{mL}$ & & no \\
HBsAg & negative & immune dueto natural & \\
anti-HBc & positive & infection & no \\
anti-HBs & positive & & \\
HBsAg & positive & chronically & \\
anti-HBc & positive & infected & $? ? ?$ \\
IgM anti-HBc & negative & & \\
anti-HBs & negative & & \\
HBsAg & negative & five & \\
anti-HBc & positive & interpretations & \\
anti-HBs & negative & possible $\dagger$ & \\
\hline
\end{tabular}


b. Anti $\mathrm{HBc}$ positive indicates $\mathrm{HBV}$ infection of a person; it may be ongoing or previous infection or resolved infection.

c. Anti $\mathrm{HBc}$ positive with $\mathrm{HBs} \mathrm{Ag}$ positive indicates ongoing infection.

d. HBsAg negative and Anti $\mathrm{HBc}$ positive indicate previous infection or resolved HBV infection. High degree of suspicion of chronic liver disease, co infection with other viruses (HCV) and immunosuppressive condition necessitates further evaluation.

e. HBV DNA screening may be required some special populations with Anti HBc positive condition.

f. Isolated Anti $\mathrm{HBc}$ positive chronic hepatitis $\mathrm{C}$ patient on DAA should be monitor for ALT. If ALT is raised despite undetectable HCV RNA; HBV DNA is recommended.

g. Monitor for reactivation by HBsAg and HBV DNA and treat if clinically evident positivity.

h. Anti viral prophylaxis is recommended over monitoring. Treatment should be continued for 6 months after discontinuation of immunosuppressive therapy

j. Prophylactic antiviral therapy is recommended for Isolated Anti $\mathrm{HBc}$ total positive (HBsAg negative and anti-HBc positive) patients to prevent reactivation of $\mathrm{HBV}$ in moderate to high risk group who are on immunosupressive therapy. Anti viral therapy should be tTAFTDF or entecavir

k. Screening for HCC should be strengthened in Anti $\mathrm{HBc}$ positive patient with cirrhosis or with Anti $\mathrm{HBc}$ and $\mathrm{HCV}$ co infection.

1. Anti $\mathrm{HBc}$ is not yet recommended as screening test for HBV in Bangladesh for blood transfusion. It may be included for prevention of transmission of HBV with blood transfusion.

m. Solid organ transplant recipient with anti $\mathrm{HBc}$ positive should continue anti-viral prophylaxis according to their immunosuppressive condition.

n. Anti $\mathrm{HBc}$ testing may be proposed in addition to HBsAg before vaccination of HBV. HBsAg negative, Anti $\mathrm{HBs}$ negative necessitates $\mathrm{HBV}$ vaccination. HBsAg negative, Anti HBcpositive and Anti HBs positive does not require vaccination. But in case of HBsAg negative, Anti HBcpositive and Anti HBs negative may not require vaccination.

Conclusion:

Anti $\mathrm{HBc}$ positivity is very common in Bangladesh. It includes several spectrums of clinical conditions and related with major issues those have clinical significance. Screening for Anti $\mathrm{HBc}$ is mandatory for $\mathrm{HBV}$ evaluation, organ transplantation and $\mathrm{HCV}$ therapy. Anti HBc is found in different phase of HBV infection, acute, chronic, resolved HBV infection, occult $\mathrm{HBV}$ infection.High degree of suspicion of HBV infection with ongoing chronic liver disease in absence HBsAg requires further evaluation. HBV DNA testing and anti viral therapy for HBV is necessary during immunosuppressive therapy. Anti HBc screening should be included for blood transfusion and HBV vaccination.

\section{Acknowledgements:}

Hepatology Society. Dhaka. Bangladesh

\section{Reference:}

1. LokA S F. Hepatitis B. In: Doolley J S, Lok A S F, Tsao G G, Pinzani M: Sherlock's diseases of Liver and Billiary System. Oxford: John Wiley \& Sons, 2018.

2. Ahmad N, Alam S, Mustafa G, et al. Seroprevalence of Hepatitis B virus in Parents and Under 5 years $\mathrm{n}$ Rural area of Bangladesh. BSMMU J 2011;4(1):8-11.

3. Mahtab M, Rahman S, Karim M F, et al Epidemiology of hepatitis B virus in Bangladeshi general population. Hepatobiliary\&Pancreatic Diseases International 2008; 7 : 595-600.

4. Rabbi F J, Alam M M,RezwanK,et al. Hepatitis B Virus Infection and Anti-HBc (Total)Positivity in CKD Patients before Dialysis. Journal of Enam Medical College 2016;6(9).

5. Ghosh D K, Ghosh C K, Nath M, et al. Prevalence of Anti$\mathrm{HBc}$ Total Positivity in an Impoverished Urban Community in Bangladesh. Bangladesh Medical Research Council Bulletin 2017; 42:63-70.

6. Wu T, Kwok R M, Tran TT. Isolated anti-HBc: The Relevance of Hepatitis B Core Antibody-A Review of New Issues. Am J Gastroenterol 2017; 112:1780-1788.

7. Gounder PP, Bulkow LR, McMahon BJ. Letter: hepatitis B surface seroclearance does reduce the risk of hepatocellular carcinoma authors' reply. Aliment PharmacolTher 2016; 44:650-651

8. Nathanson MH, Terrault N. Hepatitis B surface antigen loss:not all that we hoped it would be. Hepatology 2016; 64:32. 
9. Gandhi RT, Wurcel A, McGovern B, et al. Low prevalence of ongoing hepatitis B viremia in HIV-positive individuals with isolated antibody to hepatitis B coreantigen. J Acquir Immune DeficSyndr 2003;34:439-441.

10. McMahon BJ, Parkinson AJ, Helminiak C, et al. Response to hepatitis $\mathrm{B}$ vaccine of persons positive for antibody to hepatitis B core antigen. Gastroenterology 1992; 103 : 590-594.

11. Raimondo G, Pollicino T, Cacciola I, Squadrito G. Occulthepatitis B virus infection. J Hepatol 2007; 46: $160-170$

12. KwakM , Kim Y.Occult hepatitis B virus infection . World J Hepatol 2014, 27; 6(12): 860-86.9

13. Makvandi M. Update on occult hepatitis B virus infection. World JGastroenterology.2016, 22(39): 8720-8734.

14. Torbenson M, Thomas DL. Occult hepatitis B. Lancet Infect Dis 2002; 2: 479-486.

15. Samal J, Kandpal M, Vivekanandan P. Molecular mechanisms underlying occult hepatitis B virus infection. ClinMicrobiol Rev 2012; 25: 142-163.

16. Conjeevaram HS, Lok AS. Occult hepatitis B virus infection: a hidden menace? Hepatology 2001; 34: 204-206.

17. Kang SY, Kim MH, Lee WI. The prevalence of Anti- HBc alone in Korea. J MedVirol 2010, 82:1508-1514.

18. Jilg W, Hottentrager B, Weinberger K et al. Prevalence of markers ofhepatitis B in the adult German population. J Med Virol 2001;63:96 - 102.

19. Kleinman SH, Kuhns M, Todd DS et al. Retrovirus Epidemiology DonorStudy. Frequency of HBV DNA detection in US blood donors testing positivefor the presence of anti-HBc: implications for transfusion transmissionand donor screening. Transfusion 2003;43: $696-704$.

20. Alhababi F, Sallam TA, Tong CY. The significance of 'anti$\mathrm{HBc}$ only' in the clinical virology laboratory. J ClinVirol 2003;27:162-9.

21. Garcia-MontalvoBM ,Farfan-Ale JA, Acosta-Viana KY et al. Hepatitis Bvirus DNA in blood donors with anti-HBc as a possible indicator of active hepatitis $\mathrm{B}$ virus infection in Yucatan, Mexico . Transfus Med 2005; 15:371 - 8 .

22. Banerjee A, Chandra PK, Datta S et al. Frequency and significance of hepatitis B virus surface gene variant circulating among 'antiHBc only 'individuals in Eastern India. J ClinVirol 2007; 40: 312-7.
23. Gibney KB, Torresi J, Lemoh C et al. Isolated core antibody hepatitis Bin sub-Saharan African immigrants. J Med Virol 2008; 80:1565 - 9 .

24. Ramezani A, Banifazl M, Eslamifar A et al. Serological pattern of anti-HBc alone infers occult hepatitis B virus infection in high-risk individuals in Iran. J Infect DevCtries 2010;4:658 - 61 .

25. KishkR ,Nemr N, Elkady A et al. Hepatitis B surface gene variants isolated from blood donors with overt and occult HBV infection in north eastern Egypt . Virol J 2015;12:153.

26. Jutavijittum $\mathrm{P}$, Andernach IE, Yousukh A et al. Occult hepatitis B infectionsamong blood donors in Lao PDR. Vox Sang 2014;106:31- 7.

27. Norah A, Terrault, Lok ASF et al. Update on Prevention, Diagnosisand treatment of Chronic Hepatitis B: AASLD 2018 Hepatitis B Guidance. Hepatology Practice Guideline $2018 ; 67: 4$.

28. AASLD-IDSA. HCV Guidance: Recommendations for testing, managing, and treating hepatitis C. http:// hcvguidelines.org/full-report/monitoring-patients-who-arestarting-hepatitis-c-treatment-are-treatmentor-have Accessed4 April 2017.

29. Reddy KR, Beavers KL, Hammond SP et al. American GastroenterologicalAssociation Institute guideline on the prevention and treatment of hepatitis B. virus reactivation during immunosuppressive drugtherapy. Gastroenterology $2015 ; 148: 215-9$.

30. Coppola N, Onorato L, Sagnelli C et al. Association between anti-HBc positivity and hepatocellular carcinoma in HBsAg-negative subjects with chronic liver disease A metaanalysis.. $2016 \mathrm{Jul}$; 95(30).

31. Delavari M, Nejad N S, Andre MN et al. Frequency of AntiHBc\& HBV DNA detection in blood donors of Kerman province, Iran. Journal of Blood Disorders \& Transfusion 2011; 2:1.

32. Food and Drug Administration.Use of Nucleic acid Test to reduce the Risk of Transmission of Hepatitis B Virus from Donars of Human Cells, and Cellular and Tissue Based Products. http://www.fda.gov/BiologicsBloodVaccine/ GuidanceComplianceRegulatoryInformation/Guidence/ default.htm.(August 2016)

33. EASL 2017 Clinical Practice Guidelines on the management of Hepatitis B virus infection. Journal of Hepatology 2017; 67:370-398.

34. www.immunize.org/catg.d/p4090.pdf • Item \#P4090 (8/18) 